\title{
Phormidium autumnale (Cyanobacteria) defense against three ciliate grazer species
}

\author{
Agnieszka Pajdak-Stós*, Edyta Fiałkowska, Janusz Fyda \\ Department of Hydrobiology, Institute of Environmental Sciences, Jagiellonian University, Gronostajowa 3, \\ 30-387 Krakow, Poland
}

\begin{abstract}
Investigations of the effects of grazing by 3 species of ciliates-Pseudomicrothorax dubius Peck, Nassula citrea Kahl and Furgasonia blochmanni Faure-Fremiet-on mats of Phormidium autumnale (Agardh) Gomont showed that the cyanobacterium was capable of surviving very strong grazer pressure, thanks to both an extracellular polysaccharide (EPS) layer and behavioral defense. In the presence of ciliates, cyanobacteria trichomes were confined to a protective layer of extracellular material enclosing the mat. Trichomes attacked by a ciliate usually escaped by retreating within the EPS layer. The effectiveness of this kind of defense was reflected in dramatic changes in the condition of the ciliates: within $30 \mathrm{~h}$ of the start of the experiments a significant fraction was starved because they were unable to reach trichomes hidden within the shielding EPS layer.
\end{abstract}

KEY WORDS: Ciliates $\cdot$ Cyanobacteria $\cdot$ Extracellular polysaccharides $\cdot$ Defense

\section{INTRODUCTION}

Millions of years of coevolution in cyanobacteria and their grazers have made the former highly resistant to grazing by herbivores like protozoans, copepods and cladocerans. Such resistance has been attributed mainly to their filamentous morphology (Gliwicz 1980, Laybourn-Parry et al. 1987), production of toxins (Kirk \& Gilbert 1992) and formation of colonies (Dodds et al. 1995). Extracellular materials excreted by cyanobacteria and associated with the trichomes have also been seen to enhance resistance against grazers (Dodds et al. 1995). All these protective adaptations have been viewed as constitutive rather than inducible defenses.

Inducible defenses in aquatic systems have attracted much attention in recent decades, with the main focus on defenses in eucaryotes (Wiąckowski \& Szkarłat 1996, Luerling \& van Donk 1997, Wolfe et al. 1997, Fyda 1998, Wiąckowski \& Starońska 1999, see Harvell 1990 for review of earlier literature). Recently it was reported that simple organisms such as filamentous

\footnotetext{
*E-mail: stos@eko.uj.edu.pl
}

cyanobacteria are able to generate an induced defense against ciliate grazers (Fiałkowska \& Pajdak-Stós 1997). The defense mechanism is based on the trichomes' ability to withdraw inside their sheaths, most likely supplemented by accelerated production of sheath material in the presence of ciliates. Such a defense effectively protects the cyanobacteria against ciliate grazers, even those highly specialized in feeding on filamentous blue-green algae.

Closer observation of the interactions among cyanobacteria and their ciliate grazers revealed that Phormidium autumnale (Agardh) Gomont can also defend itself, but the mode of its defense is different from that described in our previous paper (Fiałkowska \& PajdakStós 1997). We noticed that most ciliates became transparent about $30 \mathrm{~h}$ after being presented with $P$. autumnale trichomes, which indicated that they were starved, in spite of the considerable amount of food still remaining in the environment. However, the remaining trichomes turned out to be concentrated inside the initial piece of mat used for feeding, which was now encapsulated in a layer of mucilage produced by the cyanobacteria. The appearance of the mucilage corresponds with the description of extracellular polysaccharides 
(EPS) given by Sutherland (1977), so this term is used in the present paper.

We designed a set of experiments to determine whether such a pattern of cyanobacterial mat depends on ciliate presence and whether it helps cyanobacteria to survive under strong grazer pressure. We used 3 different ciliate species to see if the reaction is a specific response to one grazer or a generalized defense against ciliates specialized in grazing on filamentous cyanobacteria.

\section{MATERIALS AND METHODS}

Strain 1462/10 of Phormidium autumnale (Agardh) Gomont (CCAP, Ambleside) was exposed to grazing by 3 species of ciliates: Pseudomicrothorax dubius Peck, Nassula citrea Kahl and Furgasonia blochmanni Faure-Fremiet. The cyanobacterium was cultured in BG11 medium (Stanier et al. 1971) - prepared according to a formula obtained from CCAP - on Petri dishes, where it formed thin mats on the bottom. Clones of $P$. dubius and $F$. blochmanni were obtained from single cells taken from an aquarium maintained at the Department of Hydrobiology, Jagiellonian University, Krakow, Poland. They had been fed unidentified strains of Phormidium. A clone of $N$. citrea was obtained from a single cell taken from the Vistula River in Krakow and fed an unidentified strain of Oscillatoria. The ciliates were identified after Protargol staining (Tuffrau 1967) as modified by Wilbert (1975). The $P$. dubius and $N$. citrea clones were cultured in BG11 medium. The F. blochmanni clone was cultured in Žywiec brand mineral water. All cultures were kept at a light intensity of $70 \mu \mathrm{m}$ photon $\mathrm{m}^{-2} \mathrm{~s}^{-1}$, under a 12:12 $\mathrm{h}$ light:dark regime at temperatures ranging from $26^{\circ} \mathrm{C}$ in light periods to $21^{\circ} \mathrm{C}$ in darkness.

Prior to the experiments the ciliates were fed on strain 1462/10 of Phormidium autumnale and then starved for $24 \mathrm{~h}$. Thereafter, 48 approximately equal-sized $(1 \times 1 \mathrm{~mm})$ pieces cut from the $P$. autumnale mat formed in culture were each placed in a Cell Wells (Corning) well containing $1 \mathrm{ml}$ of BG11 medium. The wells were divided into four 12-well groups, one of which served as the control; 200 ciliates, picked up individually with a pipette, were transferred into each well of the remaining 3 groups. Group I contained Pseudomicrothorax dubius, Group II Nassula citrea, and group III Furgasonia blochmanni. The mats in randomly chosen wells from each group were recorded after $2 \mathrm{~h}$. The same mats were subsequently recorded on Days 5 and 9 . Sometimes the pieces of mat did not remain flat on the well bottoms and assumed different shapes as a result of being transferred. Two sets of pictures taken in the wells with $P$. dubius illustrate this (Fig. 1).
It was very difficult to record, scale and quantify the diverse interactions among the cyanobacteria and the ciliates, so we used the ciliate condition as a simple indirect measure of how effective the cyanobacterium defense was. At the very beginning of the experiment $(0 \mathrm{~h})$ all released ciliates were starved. Two hours after releasing the ciliates, 50 randomly chosen individuals were categorized according to their state under a light microscope in situ. The fractions of cysts, satiated and starved ciliates were calculated. To minimize the risk of counting the same individuals the well bottoms were scanned and the categorisation was done in several different fields of view. All totally transparent individuals, without any visible trace of food inside the vacuoles, were categorized as starved whereas those with visible, greenish coloured food vacuoles were categorized as satiated. The procedure was repeated every $48 \mathrm{~h}$, in 3 different wells each time to assure the independence of the data. When the number of ciliates in a well was lower than 50, which occurred especially at the end of the experiment, we counted the fractions of all the individuals available. To describe precisely the reaction of individual cyanobacteria trichomes to ciliate grazing, we made 15 direct observations of single trichomes dispersed on the bottom and 15 observations of those emerging from the mat attacked by Pseudomicrothorax dubius.

We noticed that Nassula citrea changed its size considerably, so we also measured the length and the width of its cells. During the first $7 \mathrm{~d}$, we calculated the cell volumes of 15 randomly chosen individuals, and on the last day of the only 4 remaining.

For all the observations an OLYMPUS IMT-2 inverted microscope with Nomarski contrast working at total magnification of $150 \times$ was used. All the observations were recorded on VHS tape, and subsequent measurements of Nassula citrea size were taken from the recorded material with the help of MultiScan image analysis program (Computer Scanning System Ltd, Warsaw, Poland). In addition, the photographs in Figs. $1 \& 4$ were processed digitally from the recordings.

Analysis of variance (ANOVA) made on $\arcsin \sqrt{p}$ (where $p$ is a proportion) transformed data (Sokal \& Rohlf 1981) was used to check whether the ciliates' condition changed significantly throughout the experiments as an effect of blue-green algae selfdefense. For the calculations we employed the following: the proportion of cysts out of all counted ciliates, and the proportion of satiated individuals out of all non-encysted ones as measures of the grazers' condition. ANOVA on non-transformed data was used to analyze changes in the cell volume of Nassula citrea. 


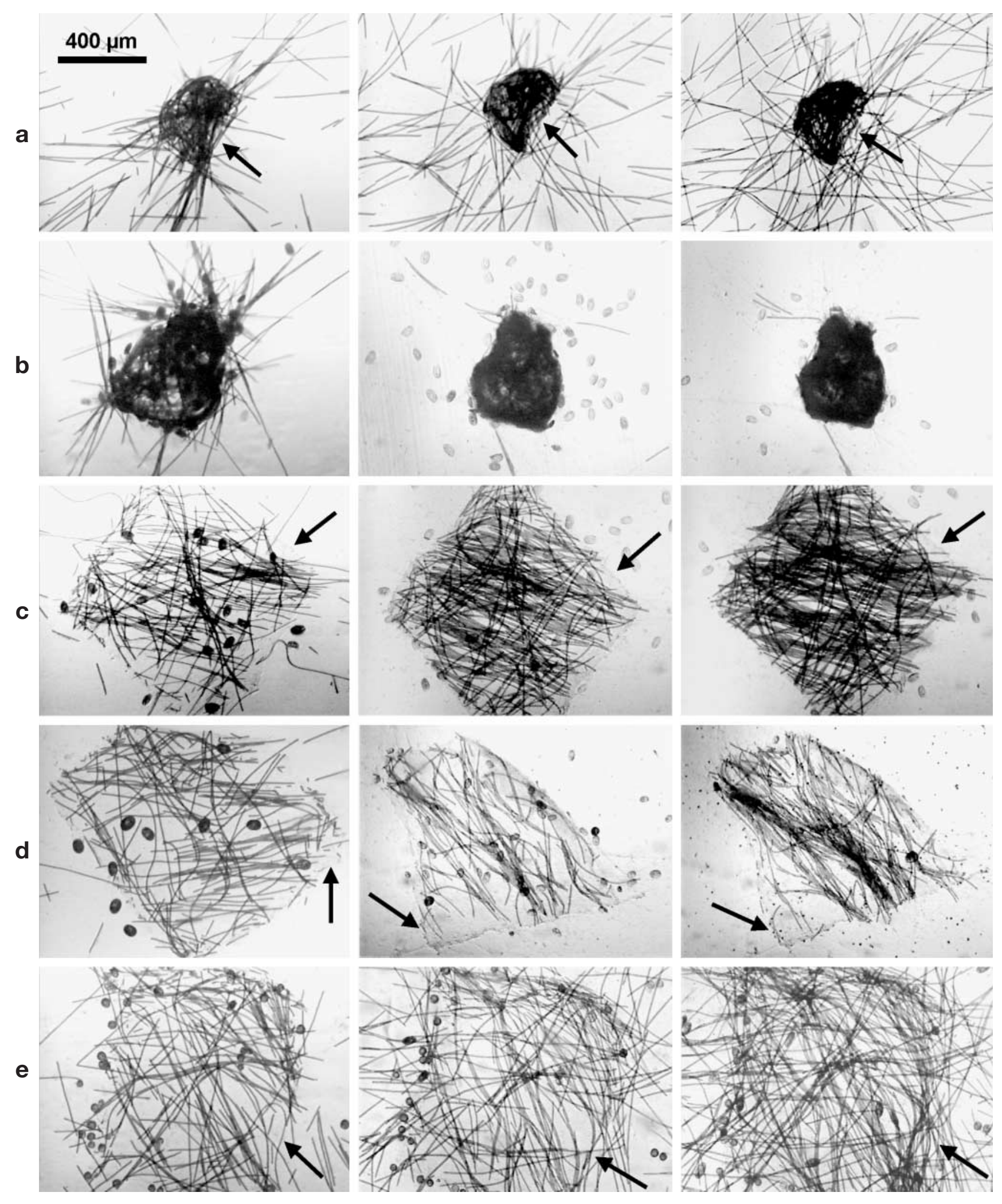

Fig. 1. Changes in the appearance of cyanobacteria mats in (a) control wells and, (b,c) wells with Pseudomicrothorax dubius, (d) Nassula citrea or (e) Furgasonia blochmanni throughout the experiment. From left to right: $2 \mathrm{~h}$ after the ciliates were introduced; Day 5; Day 9. Arrows show the extracellular polysaccharide (EPS) layer. Note the increasing density of trichomes limited to an initial piece of mat in the presence of P. dubius (c) and N. citrea (d) 


\section{RESULTS}

There were significant differences in the appearance of cyanobacteria mats subjected to grazer pressure (Fig. 1). In the control wells, without ciliate grazing, the trichomes dispersed from the initial piece of mat over the whole bottom. Their density increased noticeably throughout the experiment (Fig. 1a). When the cyanobacteria were exposed to Pseudomicrothorax dubius, single trichomes were scattered around the mat on the first day. In the next $3 \mathrm{~d}$ those trichomes disappeared and the remaining ones were limited to the original piece of mat, no matter what shape the mats had assumed at the beginning of the experiment (Fig. 1b,c). Those original pieces of mat were surrounded by a layer consisting of EPS (arrows in Fig. 1). Single trichomes next to the piece of mat appeared again on the last day. The density of trichomes inside the mat increased considerably throughout the experiment. Fully satiated ciliates were visible only on the first day (Fig. 1b,c).

In the experimental groups with Nassula citrea as the grazer, the trichomes were noticeably restricted to the EPS layer from the first day onwards, and completely restricted from the fifth day onwards. Some satiated ciliates were visible on the first and also on the following days (Fig. 1d).

The situation was completely different in the cyanobacteria mats subjected to Furgasonia blochmanni grazing pressure (Fig. 1e). On the first day there were many cysts, situated mainly at the edge of the mat. The trichomes dispersed around the mat and their density increased evenly on the bottom, as in the control wells. Live, satiated ciliates were visible mainly towards the end of the experiment but they were rare.

Pseudomicrothorax Nassula $\square$ Furgasonia

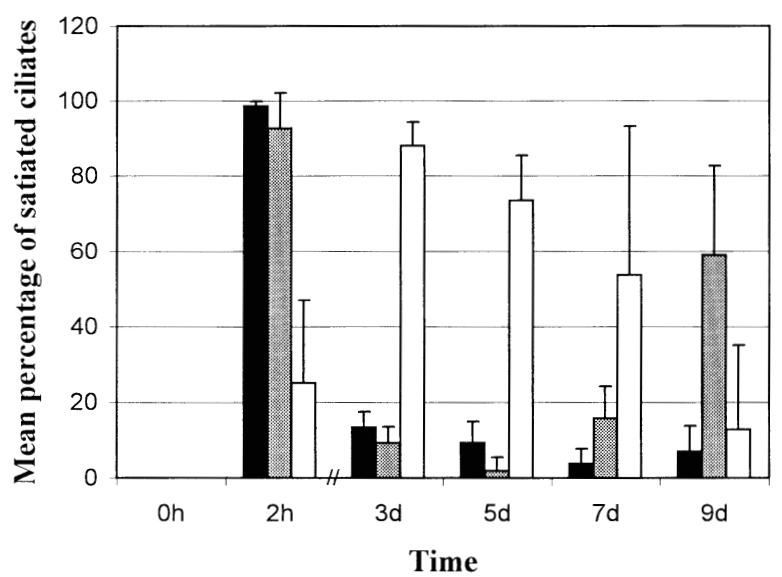

Fig. 2. Effectiveness of cyanobacteria defense as measured by the average percentage of satiated ciliates calculated for 3 repetitions. Error bars indicate standard deviations
The fractions of satiated ciliates changed significantly with the length of time the cyanobacteria were exposed to grazing (Fig. 2). ANOVA showed that this effect was highly significant in Pseudomicrothorax dubius and in Nassula citrea, whereas in Furgasonia blochmanni the effect of time was weaker but still significant (Table 1).

During the first $2 \mathrm{~h}$ of the experiment the fraction of satiated Pseudomicrothorax dubius and Nassula citrea increased significantly (Tukey HSD test, p < 0.01) (Fig. 2). The corresponding difference in Furgasonia blochmanni was not significant. The pattern changed dramatically over the next $48 \mathrm{~h}$, during which the fraction of satiated $P$. dubius decreased sharply $(\mathrm{p}<0.01)$. A similar pattern was observed in $N$. citrea $(\mathrm{p}<0.01)$. The difference between the fraction of satiated $F$. blochmanni on Days 3 and 5 was not significant. However, it was significant between the start of the experiment and the Day $3(p<0.01)$. On Day 7 the fraction of satiated $P$. dubius and $N$. citrea hardly changed at all (Fig. 2). There was no significant change in the fraction of satiated F. blochmanni on Days 7 and 9. On the last day of the experiment the fraction of satiated P. dubius remained very low, whereas in $N$. citrea it increased significantly $(\mathrm{p}<0.05)$.

The fraction of cysts in Pseudomicrothorax dubius and Furgasonia blochmanni changed throughout the experiment (Table 1). The difference in the fraction of F. blochmanni cysts during the first $2 \mathrm{~h}$ was highly significant $(\mathrm{p}<0.01)$. Later the fraction of cysts remained at the same level until the last day of the experiment. In the case of $P$. dubius there was a significant difference between Days 3 and $5(\mathrm{p}<0.01)$ as well as Days 5 and $7(\mathrm{p}<0.05)$. The changes in the fraction of Nassula citrea cysts were not significant and the cysts were very rare (Fig. 3).

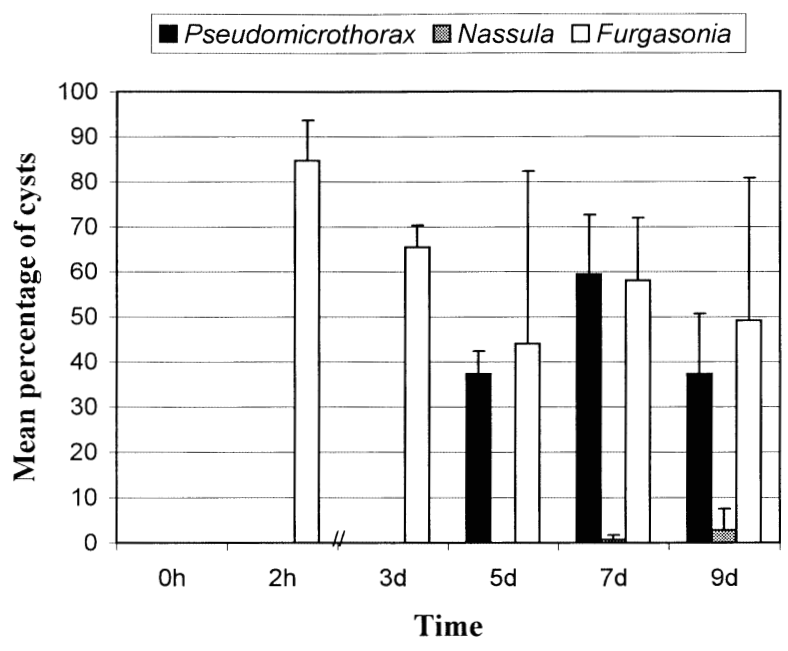

Fig. 3. Percentage of ciliate cysts calculated as mean of 3 repetitions. Error bars indicate standard deviations 

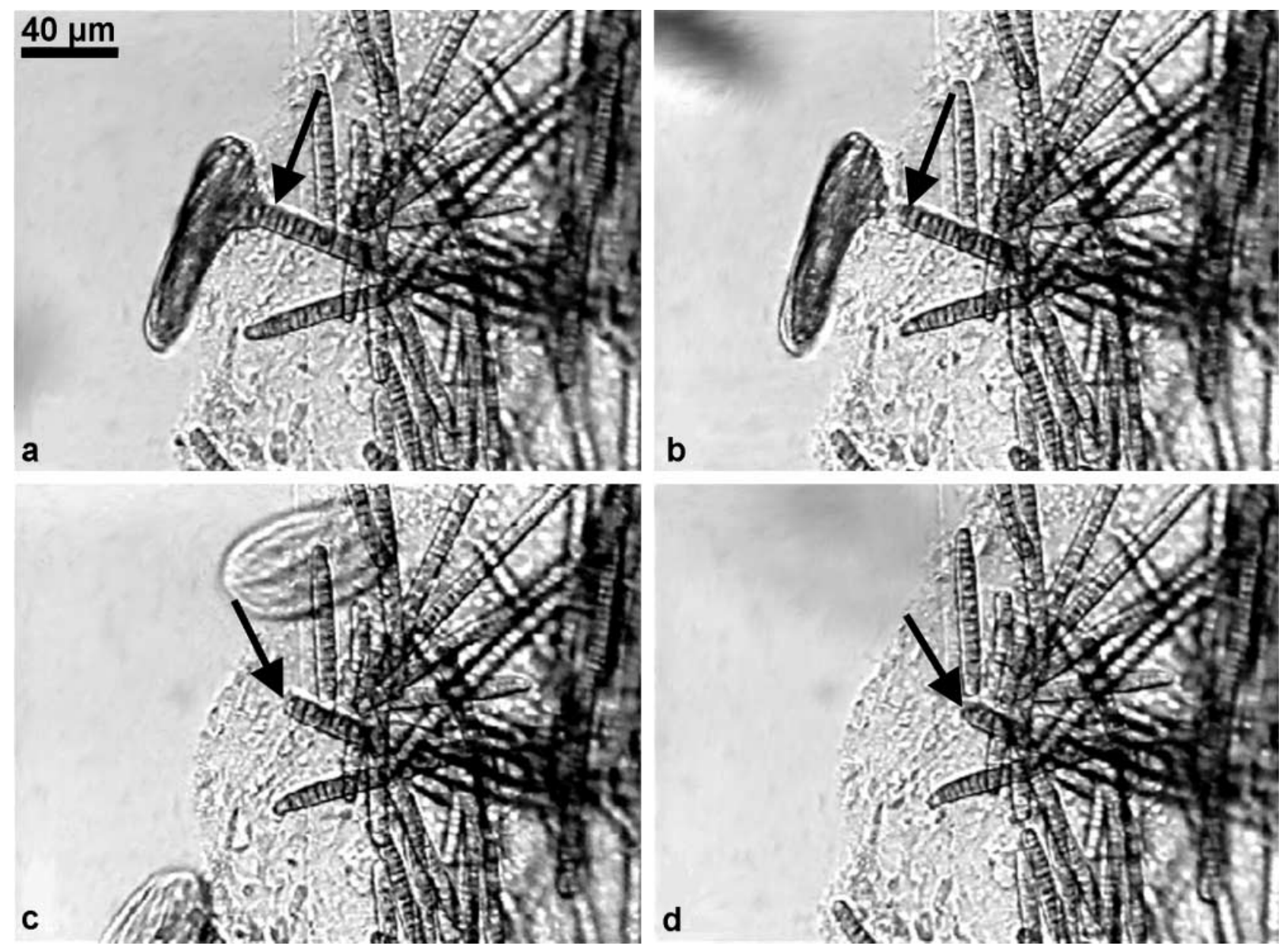

Fig. 4. Role of the EPS layer in cyanobacteria defense against a ciliate grazer. (a) Pseudomicrothorax dubius ingests a trichome to the edge of the EPS; (b) the ciliate cuts the trichome at the edge of the EPS; (c) the trichome indicated by an arrow withdraws inside the EPS - the position of trichome after $8 s_{i}$ (d) the position of trichome after $22 \mathrm{~s}$

Direct observations revealed that in all the cases a trichome attacked by a ciliate started to move in the direction opposite to that from which the attack came, no matter if the trichome was sticking out of the mat (Fig. 4) or if it was lying separately on the well bottom.

Fig. 5 shows the changes in the volume of Nassula citrea during the experiment. The changes were statistically significant (ANOVA, $F_{4,12}=3.77, \mathrm{p}<0.05$ ). The mean volume of $N$. citrea cells was significantly (Tukey HSD test, $\mathrm{p}<0.05$ ) lower on Days 5 and 7 compared to the first measurement $2 \mathrm{~h}$ after the ciliates were released into the experimental wells.

\section{DISCUSSION}

The extent of the grazing pressure exerted by the ciliates on the cyanobacteria was evident when we compared the mats exposed to Pseudomicrothorax dubius

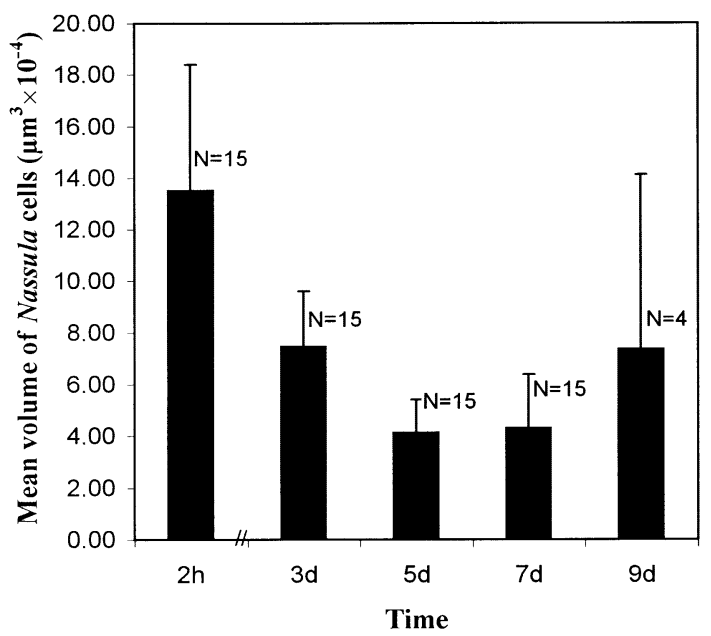

Fig. 5. Changes in the mean volume of Nassula citrea cells during the experiment. Numbers above the bars show the number of replicates. Error bars indicate standard deviations 
Table 1. ANOVA results for changes in the condition of ciliates over time presented in Figs. 2 \& 3

\begin{tabular}{|c|c|c|c|c|c|c|c|}
\hline Ciliate species & $\mathrm{N}$ & df effect & MS effect & df error & MS error & $F$ & $\mathrm{p}$ \\
\hline \multicolumn{8}{|l|}{ Satiated } \\
\hline Pseudomicrothorax dubius & 3 & 5 & 0.84362 & 10 & 0.00684 & 123.39 & 0.00000 \\
\hline Nassula citrea & 3 & 5 & 0.8121 & 10 & 0.01819 & 44.64 & 0.00000 \\
\hline Furgasonia blochmanni & 3 & 5 & 0.69041 & 10 & 0.10011 & 6.89 & 0.00494 \\
\hline \multicolumn{8}{|l|}{ Cysts } \\
\hline Pseudomicrothorax dubius & 3 & 5 & 0.50116 & 10 & 0.00541 & 92.59 & 0.00000 \\
\hline Nassula citrea & 3 & 5 & 0.00495 & 10 & 0.00495 & 1.00 & 0.45611 \\
\hline Furgasonia blochmanni & 3 & 5 & 0.4872 & 10 & 0.09029 & 5.39 & 0.01157 \\
\hline
\end{tabular}

and Nassula citrea with the mats in the control wells. The undisturbed trichomes in the control wells expanded evenly all over the bottom, and the density of those inside the initial pieces of mat apparently did not change, whereas in mats under ciliate pressure the density of trichomes inside the initial pieces of mat increased at the end of the experiment (Fig. 1).

The experiments showed that Phormidium autumnale is capable of effectively defending itself against grazers, such as Pseudomicrothorax dubius and Nassula citrea, which are highly specialized to feed on filamentous blue-green algae. The grazers were able to feed on the cyanobacteria for only a short period after their release, when a very high fraction of satiated ciliates was observed (Fig. 1). Judging by the very low number of single trichomes scattered around the piece of mat in the P. dubius treatment after the first $2 \mathrm{~h}$, and the even lower number in the $N$. citrea treatment, the grazers were able to ingest mainly single trichomes which had left the initial piece of mat consisting of trichomes and mucilaginous EPS. The exocellular substances excreted by $P$. autumnale seem to play an important defensive role by sheltering the trichomes against ciliate grazers. An additional set of pictures taken during the experiments with P. dubius (Fig. 1b,c) is included to show that the difference in mat shape between the control and the experimental wells, visible from the very beginning, is probably an artifact originating from the transfer procedure. Flat pieces of mat became immediately stuck to the bottom and remained so throughout the experiment, whereas folded ones adhered to the bottom only partially. In wells with ciliates, web-like mucilaginous material appeared at the edge of the mat, providing an extra support. No matter what shape the piece of mat adopted, there were no differences in the tendency of trichomes to disperse, or in the effectiveness of their defense, reflected in the sharp decrease in the fraction of satiated ciliates on the second day of the experiment. Fig. 4 shows the mechanism of this defense. When $P$. dubius succeeded in attacking and ingesting a trichome sticking out of the EPS shelter, the remain- ing piece of trichome immediately moved backwards and remained inside the shelter where it was inaccessible to the grazer. Direct observations showed that the reaction of the attacked trichome was always to move back from the place it was cut, no matter if the trichome was one of those sticking out of the EPS matrix or a single one lying on the bottom.

The lower number of trichomes visible inside the EPS layer after $2 \mathrm{~h}$ of Nassula citrea grazing can be interpreted as a result of the ciliate's ability to suck out longer pieces of trichomes. Nonetheless, the final effect was always the same: the grazers starved despite an apparent surplus of food. Pseudomicrothorax dubius reacted to starvation by encysting, which started on the fourth day of the experiment, whereas $N$. citrea got smaller. According to Fenchel (1987), in ciliates a decrease in cell volume and encystment are adaptations to survive the period of food deprivation. The high fraction of hungry ciliates from the third day to the end of the experiment testifies the effectiveness of the cyanobacteria's defense. They were able to survive under grazer pressure and also to multiply inside the EPS shelter (Fig. 1).

It is worth noting that the behavior of the cyanobacteria ensured the survival of the ciliates. When the pressure from the ciliates lessened due to their encystment, size decrease or weak condition, cyanobacteria trichomes began to emerge from the EPS film, which made them vulnerable to grazer attack and provided sufficient food for ciliate to survive. Consequently, the fraction of satiated Nassula citrea ciliates increased on the last day of the experiment (Fig. 2). Those results along with direct observations made on Pseudomicrothorax dubius attacking cyanobacteria trichomes suggest that trichomes growing inside the EPS matrix and those scattered individually on the well bottom are in fact equally edible for ciliates. What ensures the survival of the former is the EPS layer which makes them inaccessible for grazers.

In comparison to other species, the fraction of satiated Furgasonia blochmanni increased sharply $48 \mathrm{~h}$ later and then fell only slightly (Fig. 2). Most probably that 
happened because of encystment which occurred at the beginning of experiment, and was possibly triggered by the sudden change of medium. Decreased grazing pressure was clearly reflected in the appearance of the mats, which were less dense and surrounded by single trichomes. An abundance of unprotected trichomes along with a low number of live ciliates was the reason why the fraction of satiated ciliates was so high. Apparently the single unprotected trichomes dispersing on the bottom were easily found and consumed.

A comparison of the cyanobacteria mats subjected to high grazer pressure with those in the control wells suggests that the defensive reaction of the cyanobacteria was induced by the presence of ciliates attacking trichomes. In our previous work on 2 other species of Phormidium (Fiałkowska \& Pajdak-Stós 1997) we described a mechanism of inducible defense based on the production of stiff, strong sheaths and the ability of the trichomes to withdraw inside them. Unlike those species, $P$. autumnale produces much softer sheaths and a considerable amount of extracellular material in the form of mucilage. Although the mode of cyanobacteria defense differs clearly between species depending on morphological differences between them, the basic mechanism is always the same-cyanobacteria's ability to move.

When pieces of mat were subjected to ciliate pressure, a mixture of sheaths and mucilage created an effective shelter for the trichomes. The EPS layer (arrows in Fig. 1c,d) became more distinct in the wells where the cyanobacteria were under intense grazers pressure. It did not happen when ciliates were absent or their number was very low. In such cases a thin mucilage layer was visible at the start of the experiment and it remained unchanged until the end (arrows in Fig. 1a,e).

Our results do not provide an answer to whether the accumulation or production of mucilage could be accelerated in the presence of a ciliate. Haeder \& Hoiczyk (1992) suggest that the production of mucilage is connected with trichome movements. Castenholz (1982) says that the back and forth movements of a trichome can thicken its sheath by adding new material to the inside. This might explain why the EPS layer became more distinct in the course of the experiment as well as the development of delicate sheaths at the edge of the mats. When the number of ciliates was high, the constantly disturbed trichomes kept moving back and forth inside their sheaths within the initial piece of mat, depositing more and more mucilage on a small area. When not disturbed, the trichomes moved over a large area of the well bottom, so the expelled mucilage was evenly dispersed all over the bottom. However the EPS shelter was formed, it is clear that such a layer of mucilage ensures the survival of trichomes subjected to high grazer pressure.
Dodds et al. (1995) noted that the dense mucilage produced by and associated with Nostoc trichomes plays an important role in their resistance to predation. Because the mucilage production by Nostoc seems to be independent of grazer presence, it was treated as a constitutive rather than inducible defense. Our results support the hypothesis that the mucilage forming sheaths or amorphous layer used as a temporary shelter is a form of behavioural defense against grazers. Without grazer pressure the trichomes are not restricted to the shelter of the mucilage layer. Trichomes hidden inside the mucilage tend to leave their dens as soon as the frequency of grazer attacks decreases. The experiments showed that although ciliates feeding preferably on filamentous cyanobacteria (Brabrand et al. 1983) are potentially capable of limiting their colonization in the natural habitats, they cannot eliminate them completely. Conditions there are not as extreme as in our experiments. On the one hand, in the environment there is food other than cyanobacteria available for ciliates, which possess the ability to feed on algae (Foissner at al. 1994); that helps more of them to survive periods when cyanobacteria are inaccessible. On the other hand, because other food is available, ciliate pressure on cyanobacteria may be weaker than that observed at the beginning of our experiments, which enables cyanobacteria to disperse and colonize new areas.

Our results suggest that the cyanobacteria slime, one of the main functions of which is to facilitate movement, can also play an important role in cyanobacteria defense against grazers. The example of Furgasonia blochmanni, as well as direct observations of Pseudomicrothorax dubius feeding on Phormidium autumnale, suggest that such defense can be induced by direct contact between the grazer and its prey. The potential role of factors such as chemical signals in the defensive reaction requires more detailed studies. In any case, the described mode of defense is apparently effective enough to ensure the survival and multiplication of cyanobacteria under ciliate pressure.

Acknowledgements. We thank J. Kozłowski and W. Fiałkowski for many valuable comments made on an earlier version of this paper, and M. Jacobs for help in editing it. The manuscript also benefited greatly from the comments of referees. This work was supported by grant BW/INOS/UJ.

\section{LITERATURE CITED}

Brabrand A, Faafeng BA, Kaellqvist T, Nilssen JP (1983) Biological control of undesirable cyanobacteria in culturally eutrophic lakes. Oecologia 60:1-5

Castenholz RW (1982) Motility and taxes. In: Carr NG, Whitton BA (eds) The biology of Cyanobacteria. Blackwell Scientific Publications, Oxford, p 413-439 
Dodds WK, Gudder DA, Mollenhauer D (1995) The ecology of Nostoc. J Phycol 31:2-18

Fenchel T (1987) Ecological physiology: other aspects. In: Fenchel T (ed) Ecology of Protozoa. Science Tech. Publishers, Madison, WI, p 63-75

Fiałkowska E, Pajdak-Stós A (1997) Inducible defence against a ciliate grazer, $P$. dubius, in two strains of Phormidium (Cyanobacteria). Proc R Soc Lond B 264:937-941

Foissner W, Berger H, Kohman F (1994) Ordnung Nassulida. In: Foissner W, Berger H, Kohman F (eds) Taxonomische und ökologische Revision der Ciliaten des Saprobiensystem. Bayerisches Landesamt für Wasserwirtschaft, Munich, p 415-484

Fyda J (1998) Predator-induced morphological changes in the ciliate Colpidium (Protozoa, Ciliophora). Eur J Protistol 34: 111-117

Gliwicz AM (1980) Filtering rates, food size selection and feeding rates in cladocerans - another aspects of interspecific competition in filter-feeding zooplankton. In: Kerfoot WC (ed) Evolution and ecology of zooplankton communities. University Press of NewEngland, Hanover, p 282-291

Haeder DP, Hoiczyk E (1992) Gliding motility. In: Melkonian M (ed) Algal cell motility. Chapman \& Hall, Inc, London, p 1-38

Harvell CD (1990) The ecology and evolution of inducible defenses. Q Rev Biol 65:323-340

Kirk KL, Gilbert JJ (1992) Variation in herbivore response to chemical defences: zooplankton foraging on toxic cyanobacteria. Ecology 73(6):2208-2217

Editorial responsibility: David Caron,

Los Angeles, California, USA
Laybourn-Parry J, Jones K, Holdich JP (1987) Grazing by Maryonella sp. (Protozoa: Sarcodina) on cyanobacteria. Funct Ecol 1:99-104

Luerling M, van Donk E (1997) Morphological changes in Scenedesmus induced by infochemicals released in situ from zooplankton grazers. Limnol Oceanogr 42(4):783-788

Sokal RR, Rohlf FJ (1981) Biometry, 2nd edn. WH Freeman \& Co, New York, p 859

Stanier RY, Kunisawa M, Mandel M, Cohen-Bazire G (1971) Purification and properties of unicellular blue-green algae (order Chroococcales). Bacteriol Rev 35:171-205

Sutherland IW (1977) Bacterial exopolysaccharides-their nature and production. In: Sutherland IW (ed) Surfaces carbohydrates of the procaryotic cell. Academic Press, London, $\mathrm{p}$ 27-95

Tuffrau M (1967) Perfectionnements et pratique de la technique d'imprégnation au protargol des Infusoires Ciliés. Protistologica 3:91-98

Wiąckowski K, Starońska A (1999) The effect of predator and prey density on the induced defence of a ciliate. Funct Ecol 13:59-65

Wiąckowski K, Szkarłat M (1996) Effects of food availability on predator-induced morphological defence in the ciliate Euplotes octocarinatus (Protista). Hydrobiologia 321:47-52

Wilbert N (1975) Eine verbesserte Technik der Protargolimprägnation für Ciliaten. Mikrokosmos 6:171-182

Wolfe GV, Steinke M, Kirst GO (1997) Grazing-activated chemical defence in a unicellular marine alga. Nature 387: 894-897

Submitted: June 25, 2000; Accepted: November 8, 2000 Proofs received from author(s): February 1, 2001 